\title{
The Theoretical Underpinnings of the Influence of Customer Reward Programs on Customer Retention: A Framework and Propositions for Future Research
}

\author{
Chunqing $\mathrm{Li}^{1}$, Ping Zhao', and Junping $\mathrm{Ma}^{2}$ \\ 1 School of Economics and Management, Tsinghua University, Beijing, \\ P.R. China, 100084 \\ \{lichq, zhaop\}@em.tsinghua.edu.cn \\ 2 School of Economics and Management, Xi'an Institute of \\ Technology, Xi'an, China, 710032 \\ m_jping@163.com
}

\begin{abstract}
This paper proposes a framework and propositions for future research on the influence of customer reward programs on customer retention by reviewing the studies on the customer reward programs by employing the SEM and discrete choice dynamic programming model. This framework will give rationale and advices theoretically on how to implement relationship marketing instrument in CRM, further, it will enrich the research methods and means of related themes to enterprise information systems.
\end{abstract}

\section{Introduction}

Customer reward programs, also is known as "loyalty programs" or "frequency purchasing programs" in retailing and "frequent flyer programs" in airline. Though the specifics of these programs are different from each other, the goal of these programs is to establish a higher level of customer retention in profitable segments by providing increased satisfaction and value to certain customers [1]. Most of scholars claim that the emphasis of relationship marketing is developing, fostering long-term customers and gaining profit from the relationship in the end [2-3], and reward programs is a relationship marketing instrument which can satisfied these demand [4-5].

Please use the following format when citing this chapter:

Li, C., Zhao, P., Ma, J., 2006, in International Federation for Information

Processing, Volume 205, Rescarch and Practical Issues of Enterprisc Information Systems, eds.

Tjoa, A.M., Xu, L., Chaudhry, S., (Boston:Springer), pp.615-621. 


\section{Theoretical Backgrounds}

\subsection{Perceived Value of Reward Programs}

Some scholars proposed the influence factors of reward programs perceived value. O'Brien and Jones [6] suggested that five elements determine the value of a reward program: cash value, redemption choice, aspirational value, relevance and convenience; Dowling and Uncles [7] added psychological benefits of belonging to a program and accumulation points; Kivetz and Simonson [8] proposed that customers consider the luxury rewards are more perceived value than necessity reward; Yi and Jeon [9] claimed that the type of reward program and the time of reward program are the main factors of perceived value of reward program, and involvement moderates the effects of the factors on perceived value; Kivetz and Simonson [10] proposed the factor of "idiosyncratic fit" is an important factor.

\subsection{The Influence of Perceived Value of Reward Programs on Customer Retention Behavior}

The essential aim of customer retention is building and retaining customer loyalty, which can realize the repeat purchasing [11]. The research focus of customer retention behavior is the dependent variable of customer retention such as repeat purchasing, positive word-of-mouth, price tolerance, relationship retention during, and wallet share, etc. Currently, seldom research focuses on the influence of perceived value of reward programs on customer retention behavior, but $\mathrm{Yi}$ and Jeon's [9]. Their research results show that involvement moderates the effects of reward programs on customer loyalty.

\subsection{Quantitative Analysis of the Customer Retention via Exchange Data}

With the developing of enterprise information systems, it is possible to collect the customer exchange data and employing the mathematical model such as discrete choice model to analyze the customer behavior.

Verhoef Peter C. [5] investigates the differential effects of customer relationship perceptions and relationship marketing instruments on customer retention and customer share development over time. The SEM and the discrete choice model are both employed in the study. Bolton Ruth $\mathrm{N}$. et al. [1] develops a process model of how customers' service experiences - including their experiences with the competition and loyalty programs - influence their repatronage behavior. Lewis [12] models customers' response to a loyalty program under the assumption that purchases represent the sequential choices of customers who are solving a dynamic optimization problem. Chunqing $\mathrm{Li}$ [13] presents a dynamic customer relationship management model in a dynamic environment where customers maximize utility and the firm maximizes CLV. Lewis's [12] and Chunqing Li's [13] study all utilized a research methodology know as estimable stochastic structural dynamic programming or discrete choice dynamic programming. These methods are fairly well established in economics [14], and applied in marketing in recent years [12, 13, and 15]. 


\section{The Framework of Future Research and Research Details}

\subsection{Research Framework}

Based on the current research, we proposed a framework of future research (Fig. 1.). The vertical line divides the framework into two parts that describe two study methodologies: the left is the customer behavior model; the right is the mathematics analysis model.

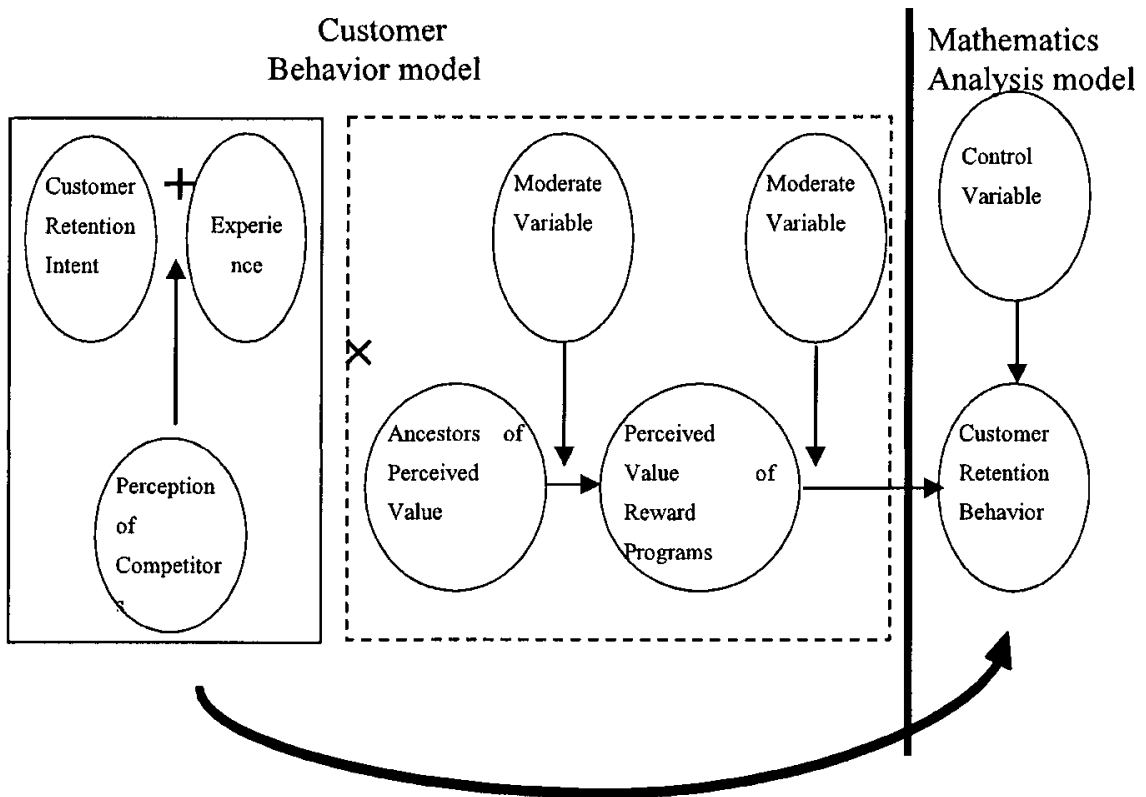

Fig. 1. The research framework of the influence of reward programs on customer retention behavior

In the left part, there are two rectangles: the real one describes the situation of considering competition, and the broken one is the contrary. The symbol "+" means customer retention intent, customer experience, and customer perception of competitors influence the customer retention behavior jointly. The symbol " $\times$ " means the influence is relative to whether customer joining the reward programs, which is a Boolean-variable in the model. If the Boolean-variable equals 0 (not joining to the reward programs), the model means exploring the effect of real rectangles on customer retention behavior, and if 1 (joining to the reward programs), means exploring the effect of both real rectangles and broken rectangles on customer retention behavior. 


\subsection{Research Details}

According to the research framework of Fig. 1, future research can be classified according to two dimensions: research method (Customer Behavior Model or Mathematics Model) and whether considering competition.

\section{Customer Behavior Model of not Considering Competition}

In this situation, the future research would include two sub-problems (Fig. 2.):

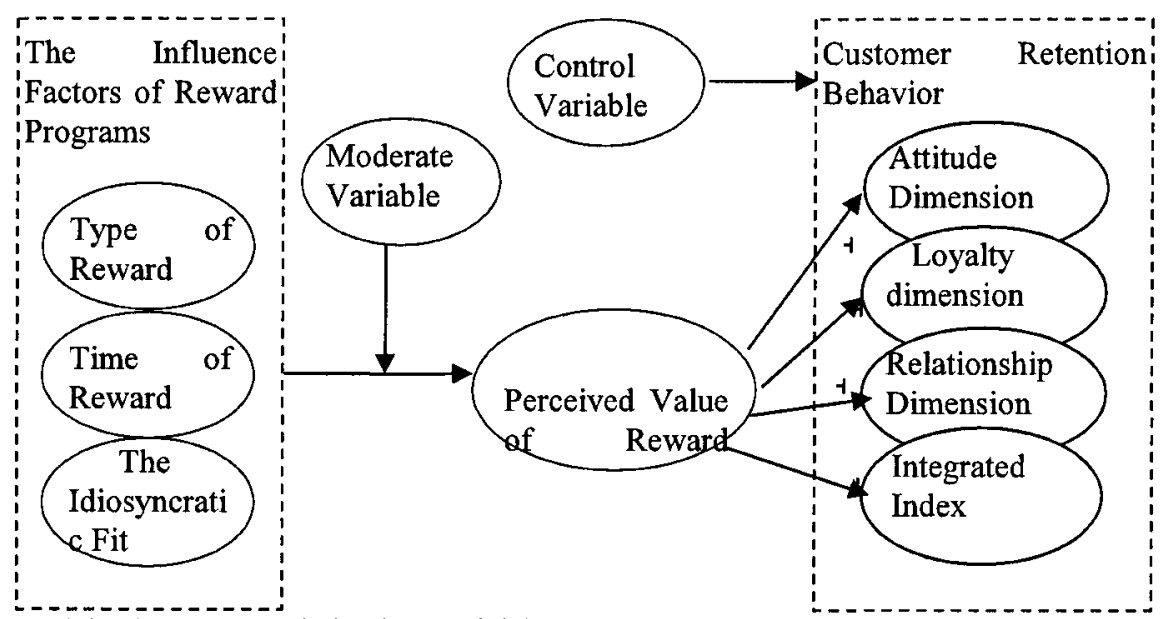

Fig. 2. Customer behavior model (Not considering competition)

Sub-problems 1: The influence of different reward programs on perceived value

In reality, the details of reward programs are different. Though the ancestors of perceived value of reward programs are not clearly defined, type of reward, time of reward and The Idiosyncratic Fit have been studied experientially. Besides of these ancestors, other factors should be explored and studied. Moreover, sometimes, the effect of moderate variables on independent variables is remarkable, so confirming moderate variables in special research environment is an important target in future.

Sub-problems 2: The influence of perceived value of reward programs on customer retention behavior

In this part, customer retention behavior can be segment to four dimensions: attitude dimension, loyalty dimension, relationship dimension and integrated index. Attitude dimension refers to relationship commitment and trust [3]. Loyalty dimension refers to customer behavior variables such as repeat purchase, cross purchase, positive word-of-mouth, price tolerance, cooperation behavior, etc. Most research claimed that reward programs would change customer behavior, enhance customer loyalty [16]. Relationship dimension refers to relationship length, relationship breadth and relationship depth [17]. Integrated index refers to customer retention rate and customer share development over time [5]. 
Based on which, we propose hypothesis: the perceived value of reward programs has a positive relation to attitude dimension, loyalty dimension, relationship dimension and integrated index.

In special research environment, how to confirm the variables in four dimensions and the scales of the variables is the key problem. Moreover, moderate variables and control variables could be put into the model of Fig. 2. After confirming the variables and scales, researchers can design the questionnaire, collect the data, test of hypotheses and analyze the goodness-of-fit of model. SEM and Lisrel can be considered in model design and analysis.

\subsubsection{Customer Behavior Model of considering competition}

In this situation, the future research model can be seen in Fig. 3:

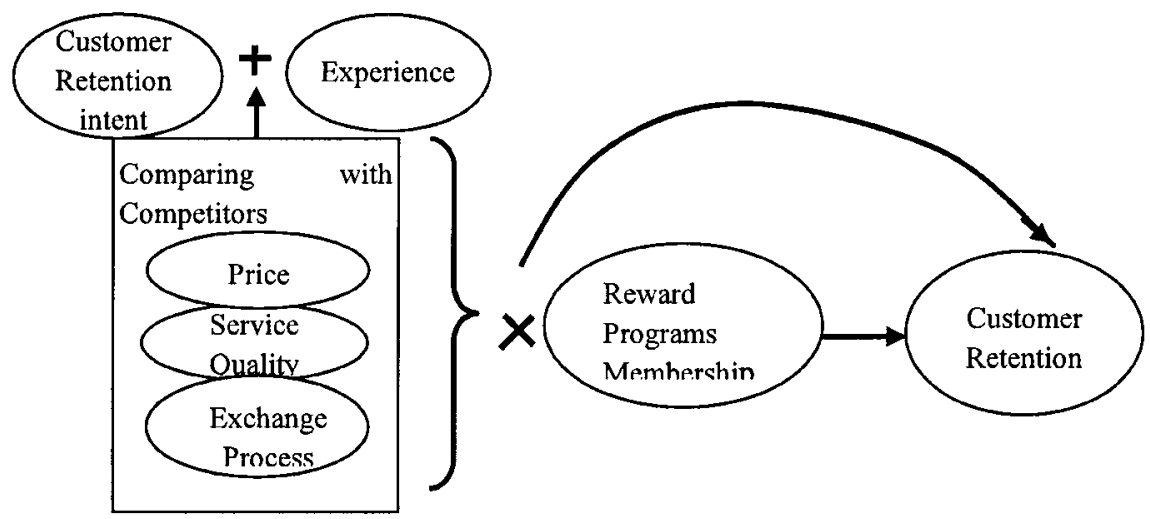

Fig. 3. Customer behavior model (considering competition)

When considering competition, the discrete choice model can be applied. Firstly, the relationship between customer and firm can be defined a state variable of 0 or 1 , that is, if the customer decides to join the reward program of next period, the state variable equal to 1 , otherwise, 0 . So, the researchers should pay more attention to the factors that influence the decision of customers. Bolton Ruth's model [1] proposed there are three aspects that decide decision of customers. They are customer retention intent, customer experience and perception of competitors. In future research, based on Bolton Ruth's model, the perceived value could be considered a new factor.

In future research, there are three problems: confirming the scales of variables, building discrete choice model and changing the questionnaire data into discrete choice model. The cause of data change is the variables of the discrete choice model may be different from the questionnaire data, or the linear combination of the questionnaire data.

The parameters of model can be confirmed with logistic regression and the goodness-of-fit can be evaluated by likelihood and fit coefficient. The advantage of the logistic regression is forecasting customer's probability of joining the reward programs in next period. 


\subsubsection{Mathematics model}

Mathematics model here refers to discrete choice dynamic programming that has advantage in the situation of "when customer considers both current and future benefit". Because of the reward, customers always have the character of "lookingforward" when they joined a reward program, therefore, researchers can study the reaction of customer on reward programs and customer's behavior change via discrete choice dynamic programming.

Generally speaking, there are three key points in building discrete choice model: confirming the variables of the model, defining the state variables and the evolution of variables and estimating the parameters of the model. About the first, researchers can conclude variables from the conception model we have proposed in 3.2.1; about the second, the key point is describing customer's state adequately by smaller state space as possible; and about the third, researcher need design mew algorithm according to detail model.

As same as conception model, we can also study the reward programs in the situation of considering competition or not here. But when considering the competition, the customer state should be adjusted and the complexity of the estimate algorithm is higher.

\section{Conclusions}

Based on reviewing the literatures about reward programs, this paper proposes a framework and propositions for future research about the influence of customer reward programs on customer retention. The framework not only explores the relation of customer perceived value on the reward programs and the outcome factors of customer retention by employing the SEM, but also develops a discrete choice dynamic programming model to forecast the customer value perception based on their exchanging data so as to reflect the dynamic process of customer retention. This framework will give rationale and advices theoretically on how to implement relationship marketing instrument in CRM, further, it will enrich the research methods and means of related themes to enterprise information systems.

\section{Acknowledgements}

This research is supported by National Natural Science Foundation of China (70572009, 70302001), Postdoctoral Science Foundation of China (2005037374), and the Education Department of Shaanxi Province (05JK046).

\section{References}

1. Bolton, Ruth N., Kannan, R K., Bramlett, Matthew D. Implications of Loyalty Program Membership and Service Experiences for Customer Retention and Value. Journal of the Academy of Marketing Science, 2000, 28 (Winter): 95-108. 
2. Garbarino, Ellen and Mark S. Johnson. The Different Role of Satisfaction, Trust, and Commitment in Customer Relationships. Journal of Marketing, 1999, 63(April): 70-87.

3. Morgan R.M. and Hunt S.D. The Commitment-Trust Theory of Relationship Marketing. Journal of Marketing. 1994, 58(July): 20-38.

4. Roberts, Mary Lou and Paul D. Berger, Direct Marketing Management [M]. Englewood Cliffs, NJ: Prentice Hall, 1999.

5. Verhoef, Peter C. Understanding the Effect of Customer Relationship Management Efforts on Customer Retention and Customer Share Development.Journal of Marketing, 2003, 67 (4): 30-45

6. O'Brien, Louise and Charles Jones. Do Rewards Really Create Loyalty? Harvard Business Review, 1995, 73(May-June): 75-82.

7. Dowling Grahame R., Mark Uncles. Do Customer Loyalty Programs Really Work? Sloan Management Review. Summer, 38, 71-82 (1997).

8. Kivetz, Ran and Itamar Simonson. Earning the Right to Indulge: Effort as a Determinant of Customer Preferences toward Frequency Program Rewards. Journal of Marketing Research 39(May), 155-170 (2002).

9. Yi Youjae, Jeon Hoseong. Effects of Loyalty Programs on Value Perception, Program Loyalty and Brand Loyalty. Journal of the Academy of Marketing Science. 2003, 31(3), 229240.

10. Kivetz, Ran and Itamar Simonson. The Idiosyncratic Fit Heuristic: Effort Advantage as a Determinant of Consumer Response to Loyalty Programs. Journal of Marketing Research. 40(4), 454-467 (2003).

11. Mingliang Chen. Customer Retention and Customer Lifetime, Xi'an Jiaotong University, 2001 ,

12. Lewis Michael. The Influence of Loyalty Programs and Short-Term Promotions on Customer Retention, Journal of Marketing Research, 2004, 41(August): 281-292.

13. Chunqing Li, Yingfeng Xu. A DCRM Model with Reward Programs in Supermarket: Development and Empirical Study. Journal of Industrial Engineering and Engineering Management, 2004,18(2):85-89

14. Rust, John. Structural Estimation of Markov Decision Processes. In: D. McFadden and R. Engle, eds. Handbook of Econometrics. Vol. 4 Amsterdam: North-Holland, 1994: 3081-3143.

15.Gönül, Fusun and Zeshi Meng. Optimal Mailing of catalogs: A new methodology using estimable structural dynamic programming models. Management Science, 1998, 44(9): 12491262.

16. Byron Sharp and Anne Sharp. Loyalty Programs and Their Impact on Repeat Purchase Loyalty Patterns. International Journal of Research in Marketing, 1997, 14, 473-486.

17. Ruth N. Bolton, Katherine N. Lemon, Peter C. Verhoef. The Theoretical Underpinnings of Customer Asset Management: A Framework and Propositions for Future Research. Journal of the Academy of Marketing Science. 32(3): 271-292. 